\title{
Coexisting with chaparral
}

\author{
Long-term studies at Hopland Research and Extension Center find no simple answers for \\ reducing fire risk while conserving biodiversity.
}

\author{
Because chapparal \\ ecosystems are \\ often found near \\ California's urban \\ areas, they are a \\ major focus for fuel \\ reduction efforts \\ such as mastication \\ treatments and \\ controlled burns. \\ Trials have been \\ conducted since \\ 2001 at HREC to \\ determine the effect \\ of these treatments \\ on biodiversity.
}

$\mathrm{M}$ ore than half of California's 20 largest wildfires have involved chaparral ecosystems. The oily shrubs burn hot - up to $3,500^{\circ} \mathrm{F}$, with flames that can reach 50 feet high.

Because chaparral is found in and around many of the state's largest population centers, chaparral systems include a great deal of what's known as wildland-urban interface. That makes chaparral a major focus of efforts to manage fire risk by reducing wildland fuels loads - typically through prescribed fire and mastication (mechanical chopping).

Chaparral is also one of California's most biodiverse ecosystem types, which sets another imperative for land managers: avoiding the degradation or loss of chaparral systems.

UC ANR's Hopland Research and Extension Center (HREC) in southern Mendocino County provides a unique experimental location to study the effects on chaparral systems of fuels reduction treatments. There's abundant chaparral on the 5,300-acre site, it's remote enough to make burning safe and practical, and researchers can conduct long-term studies; some data sets collected at HREC span more than 40 years.

Since 2001, Scott Stephens, a professor in the Department of Environmental Science, Policy and Management at UC Berkeley, and his collaborators have studied the ecosystem changes wrought by mastication treatments and more than 35 controlled fires at HREC. The fires have been managed by California Department of Forestry and Fire Protection (CAL FIRE) and REC staff.

In California's conifer forests, it's now well-established that fuels reduction treatments promote healthy ecosystem function - in part because those systems are adapted to frequent low-intensity fires that burn the underbrush and small trees.
But chaparral systems are different. They appear to be adapted to infrequent fire, recurring perhaps only every 50 or 100 years. The shrubs that define chaparral systems are slow to grow back, and that can allow nonnative grasses to establish.

Nonnative grasses are a problem because their flammability is higher than that of native grasses, and much higher than that of chaparral shrubs (which are fairly resistant to ignition but burn very hot once lit). High flammability of vegetation increases the probability of frequent accidental wildfires. Ecologists consider nonnative grasses one of the gravest threats to the diversity of a chaparral ecosystem; they can eventually convert chaparral to permanent grassland.

"They're a giant red flag for the ecosystem," said Stephens.

Ongoing trials at HREC are comparing five treatments: fall, winter and spring prescribed fire, and fall and spring mastication. The findings illustrate the multiple considerations that must inform fuels management strategy - and that no strategy is a clear winner in all situations.

For instance, while mastication provides a larger and longer-lasting fuel hazard reduction than fire, it appears to leave chaparral systems more vulnerable to invasion by nonnative grasses. 
